\title{
Protracted Transient Ischemic Attacks
}

\section{C.}

Department of Neurology, University of Genova, Genova

Prof. Dr. Carlo Loeb, Istituto di Clinica Neurologica dell'Università di Genova, I-16132 Genova (Italy)

Over the last few years various definitions have been coined to indicate ischemic attacks receding later than $24 \mathrm{~h}$ from their onset: strokes with full recovery (6th International Salzburg Conference, 1972), reversible ischemic neurological deficit (Handbook of Clinical Neurology, 1972; Ad hoc Committee on Cerebrovascular Diseases, 1975), prolonged reversible ischemic neurological deficits (International Symposium on Microsurgical Anastomoses for Cerebral Ischemia, 1974).

In spite of the relative dearth of pertinent data which permits hardly more than a preliminary formulation of the problem an attempt at placing the whole topic into proper perspective seems indeed justified.

Historical Review

A glimpse at the historical evolution of the concept of transient cerebrovascular episodes turns out to be rather disappointing. Even the interesting review by Schiller (1970) of the concept of stroke before and after Virchow did not touch upon this problem.

From ancient Greek and Roman students to the founders of the modern anatomoclinical investigation (17th-18th centuries) all who dealt with cerebrovascular disorders seemed

most concerned with severe hemorrhagic apoplexies or, at the most, with the harbingers of stroke (Caelius Aurelianus, 5th century AD; Morgagni and Boheraave, 18th century).

Transient episodes were either indirectly mentioned (42nd aphorism of Hippocrates) or briefly recalled in the clinical history (see Zani case of Morgagni letter IV) almost always being overlooked in favor of pathological studies of the completed stroke.

Only during the second half of the 19th century did transient cerebrovascular episodes come somewhat to the fore, their possible causes being grouped as follows: (a) massive extracranial hemorrhages (Durand-Fardell, 1843; Andral, 1853;Bouveret, 1899); (b) cardiac alterations (Rokitansky, 1856; Andral, 1853); (c) cerebral arterial spasms: this hypothesis put forward by Raynaud (1862) to account for the transient loss of vision was subsequently accepted by many authors (Weiss, 1882; Bland, 1889; Peabody, 1891; Osier, 1896) as the most convincing pathophysiological explanation of cerebrovascular transient episodes; in fact Wilson and Bruce (1955) devoted a whole chapter of their treatise to the cerebral spasm, and (d) neurolues (apoplectiform episodes of general palsy: Neisser, 1894; syphilithic hemiplegia: Jackson, 1888/1958). 2

The vasospasm theory held sway although among controversies (Oppenheim, 1905; Ala-jouanine and Thurel, 1936; Fazio and Loeb, 1948) up to the 1950s, being unanimously rejected when Corday and Rothenberg (1957) introduced the successful label of 'cerebrovascular insufficiency' following a similar cardiological definition by Rein (1931) and Buchner (1939).

During the 2nd Princeton Conference along with other terms such as 'intermittent vascular insufficiency', 'ischemic recurrent attacks', 'recurrent focal cerebral ischemic attacks', 'transient cerebral ischemia', the definition of'transient ischemic attacks' (Miller Fisher, 1958) was employed for the first time.

Such definition was popularized gradually: in 1958 the 'Ad hoc Committee' established by the NIH indicated the transient episodes as 'transient cerebral ischemia', in the 1961 3rd Princeton Conference the term 'focal intermittent insufficiency or ischemic attack' was still used, with only Miller Fisher employing the TIA acronym (absent from the analytical index); it was only in the 4th Princeton Conference of 1965, however, that the definition of transient ischemic attacks' gained unanimous acceptance. With respect to the duration of the episode, as long ago as 1928 Lhermitte stated that rarely it lasted more than 24 h; on the other hand Alajouanine et al. (1960) dealing with 'transient cerebral ischemia' wrote that 'in a few cases the attacks may be more prolonged persisting for several days'.

Quite recently attention has been focused on a number of cases exhibiting transient episodes which cleared completely later than $24 \mathrm{~h}$ from the onset and were labelled as 'stroke with full recovery' (6th Salzburg Conference, 1972). In the same year similar cases, although devoid of a complete clinical evaluation and follow-up were mentioned by Meyer, Guiraud and Bauer

in Vinken and de-Bruyrts Handbook of Neurology as 'reversible ischemic neurological deficits'. A few years later the same terminology was employed by an official classification of the 'Ad hoc Committee on Cerebrovascular Diseases', headed by Millikan (1975). Clinical Definition

The transient ischemic attack was classically defined as a cerebral dysfunction of ischemic nature lasting not longer than $24 \mathrm{~h}$ with a tendency to recur. The following were therefore the features essential to the definition: ischemic pathogenesis, complete reversibility, and $24 \mathrm{~h}$ duration. To conform to the definition the completeness of the regression should, first of all, be verified by the neurological examination, which should be unrevealing altogether: in other words, free from even slight abnormalities - unequality of tendon reflexes, slight pronator drifts, etc. (Loeb, 1977a).

In fact, episodes which do not recede completely, often labelled as 'minor strokes' can be brought about by small infarctions or even hemorrhages (van der Drift and Kok, 1973; Yates, 1976; Russell, 1976; Loeb, 1978b) and large softenings (Loeb, 1978b) and cannot therefore be considered as proper TIA. 
The $24 \mathrm{~h}$ limit was chosen arbitrarily; in fact quite a few authors think that usually the duration of these attacks is about $1 \mathrm{~h}$ (Hutchinson and Acheson, 1975) or even some minutes (Pessinetal, 1977).

The $24 \mathrm{~h}$ duration was chosen particularly with a view at possible therapeutic strategies such as anticoagulants or vascular surgery.

It seems clear that ischemic episodes clearing later than $24 \mathrm{~h}$ from the onset - usually within 3 weeks - require further elucidation. Such clinical pictures were indicated as 'strokes with

3 protracted Transient Ischemic Attacks

full recovery' \{Loeb andPriano, 1973, 1975) or 'reversible ischemic neurological deficits' (Millikan et al, 1975).

The definition of 'protracted transient ischemic attack' (PTIA) fits perhaps best the present clinical classification.

Therefore, the classification proposed by the NINCAS ad hoc Committee on Cerebrovascular Diseases (1975) could be modified, with respect to the description of the current state of the patients in reference to the whole temporal profile of the cerebrovascular diseases, as follows:

Clinical Stage

(A) Asymptomatic. (B) Focal cerebral dysfunction. (1) Reversible ischemic attacks (RIA): (a) transient ischemic attack (TIA); (b) protracted transient ischemic attack (PTIA). (2) Actively changing neurological deficit: (a) improving; (b) worsening (also known as stroke in evolution or progressing stroke). (3) Prolonged neurological deficit: (a) completed stroke. (C) General cerebral dysfunction, (a) Transient; (b) prolonged.

Because of the evolution of the disease it is likely that patients will be in different categories at different times. In particular, TIA and PTIA can appear in the same patient on different occasions.

PTIA in Focal Cerebrovascular Diseases; Vascular District Involved

The available data do not permit the accurate incidence and epidemiology of PTIA to be established. In our case material, out of 1,120 cases with cerebrovascular focal episodes, 102 (i.e., 9.1\%) had transient episodes labelled as reversible ischemic attacks (RIA), therefore comprising both classical TIA (67 cases, i.e., 65.7\%) and PTIA (35 cases, i.e., 34.3\%). For

this last group the duration of symptoms was more than $24 \mathrm{~h}$, namely from 1 to 60 days, 3 weeks on average.

The frequency of remitting cerebrovascular episodes (not better definable on the obvious lack of objective data) was particularly high in the history of cases with cerebrovascular disease verified at necropsy; in particular in 50 out of 126 cases with white softening, in 8 out of 33 cases with red softening, and even in 14 cases with hemorrhage. 21 males and 14 females sustained PTİAs; 22 out of these 35 occurred in patients aged from 46 to 65 years.

The carotid district was three times as frequently involved as the vertebrobasilar one ( 25 vs. 8 cases).

Clinical Features

In agreement with the report of the Joint Committee for Stroke Facilities (Heymann et al., 1974) many symptoms such as dysphagia, dysarthria and diplopia; amnesia, confusion, loss of consciousness and vertigo were not considered when they appeared alone, since they can be explained by causes other than reversible cerebral ischemia.

The duration of the episode could vary from 4 to 60 days clearing within 3 weeks in 19 out of 35 cases. A typical example is provided by case 42 , a man aged 58 years with six former TİAs in whom a right hemiparesis lasted 33 days, its complete resolution occurring after surgery of a left internal carotid stenosis (Loeb andPriano, 1973).

In the carotid district, the onset of PTIA was more gradual than that of TIA, motor disturbances could affect one side of the body, one limb, one half of the face; aphasia was often the only symptom and sensory disturbances were rare, while visual symptoms (unilateral amaurosis, hemianopia) were absent. 4

In the vertebrobasilar territory the onset of PTIA was more often abrupt, the usual clinical picture being represented by motor disturbances (of the fore or of the lower limbs, of one-half of the body or of the face) ataxia, visual disturbances (bilateral amaurosis, hemi-anopia) and sensory disturbances.

Involvement of consciousness, associated with other focal neurological signs occurred in 3 cases, with both the carotid and the vertebrobasilar territories being affected.

The EEG showed focal, bilateral or diffuse alterations in 7 out of 35 cases, the tracing reverting to normal usually within 6 days. In 7 cases the carotid compression test brought about EEG abnormalities. "Tc brain scans were only exceptionally positive for a few days in one case.

Angiography showed, in 14 cases, abnormalities such as middle cerebral artery occlusion, carotid stenosis but, above all, absence of terminal branches of the Sylvian artery (Ring, 1962).

The results of computed tomography (CT) studies in cases with TIA and PTIA deserve particular mention. A total of 138 cases with TIA examined with CT (Kinkel and Jacobs, 1976; Constant et al, 1976; Bull et al, 1976; Perrone et al; 22 personal unpublished cases) and 62 cases with PTIA or RIND (Oltenau-Nerbe etal, 1976; Penone et al;:Loeb, 1978a; 23 personal unpublished cases) have been described so far.

Most authors maintain (Liliequist, 1978) that in TIA the CT examination is unrevealing; only Perrone et al found low density lesions in $34 \%$ of cases with TIA; while $48 \%$ of cases with PTIA or RIND were found positive by Oltenau-Nerbe et al. (1976) and Perrone et al

It should be recalled that when cases with incomplete regression, namely exhibiting even slight neurological signs are erroneously included under the TIA or PTIA label, then small

infarcts or hemorrhages may be visualized by CT (Loeb, 1978a).

In our, albeit small, experience with CT in cerebrovascular disorders, this examination is always unrevealing in cases with PTIA.

Associated Diseases

In 15 out of 35 cases (i.e. $42.8 \%$ ) hypertension was present (with diastolic values exceeding $100 \mathrm{~mm} \mathrm{Hg}$ ); in 12 out of 35 cases ( $34.2 \%$ ) there were signs of cardiac involvement (ventricular hypertrophy, myocardial ischemia, recent infarction), in 9 cases dysprotidemia and in a few cases diabetes, thrombophylia, peripheral vascular disease (see Toole et al, 1975 for references).

Differential Diagnosis 
Apart from the classical differential diagnoses with focal epilepsy, migraine, hypoglycemic spells, hypertensive crisis, differentiation which PTIA share with TIA (Millikan, 1976; Russell, 1976) episodes quite similar to PTIA can occur in cerebral tumors (Loeb, 1978a).

In fact, out of 168 cases of histologically verified brain tumors $17(10.1 \%)$ had shown transient episodes of focal cerebral dysfunction. Such episodes were isolated in 10 cases and multiple in 7, totalling a number of 33 attacks in 17 patients. Of relevance to the present report is the fact that as many as 15 attacks out of 33 took $2-15$ days to recede completely.

The clinical features of these cases consisted of aphasia and/or hemiparesis, central facial paresis, loss of consciousness, hemiparesis and/ or amaurosis. The tumors were represented by 6 metastases, 6 glioblastoma, 2 meningiomas Protracted Transient Ischemic Attacks

5

and 3 astrocytomas. It is therefore obvious that at least a CT study is mandatory in all cases with transient cerebral dysfunction of any duration. Natural History and Follow-Up

A 6-year follow-up of a group of cases with TIIA (62 cases) and PTIA (32 cases) (Loeb et al, 1978, and unpublished data) permits the following remarks: (a) Multiple attacks are significantly more frequent in TIA than in PTIA. In particular, only 11 out of 32 cases of PTIA are multiple as compared with 35 out of 62 cases of TIA. Moreover, while TIA tend to recur more often in the vertebrobasilar district, in multiple PTIA preferential sites of involvement cannot be found, (b) In 8 out of 10 cases ( 1 case had attacks both in the carotid and vertebrobasilar districts) multiple PTIA recur in the same district, (c) The time interval between attacks varies from 15 days to 5 years the highest rate of relapse being within a year of the first episode, (d) The completed stroke occurred in 5 out of 32 cases (15.6\%) and considering cases with both TIA and PTIA in 11.7\% of cases (11 out of 94 cases), (e) 26 out of 32 cases (81.2\%) with PTIA are still alive, of these $24(75 \%)$ did not develop any further stroke while 8 had subsequent TİAs and/or PTIAs.

6 patients with PTIA died, their main cause of death being represented by myocardial infarction as happens to TIA cases as well (Whisnant, 1977). Pathogenesis

No attempt will be made here to discuss all the theories amply reported in several fairly

recent contributions (Paulson, 1971; Hutchinson and Acheson, 1915; Russell, 1976).

According to the majority of authors the main pathophysiological mechanism responsible for TIA is embolism or thromboembolism. A TIA, therefore, is the outcome of a critical fall of cerebral PaC\&gt; 2 brought about by reduction of the cerebral blood flow (CBF) in its turn determined by a transient thromboembolism of the involved artery.

The critical CBF values are influenced by: (a) modality — i.e., sudden or gradual — of onset; (b) efficiency of the collateral circulation, contributed to, among other factors by the adequacy of the cardiac function and systemic pressure; (c) arterial blood $\mathrm{O}_{2}$ saturation and (d) efficiency of the autoregulation mechanism and of the vasodilatory response to hypoxia.

According to the embolic theory, in the intervals between TIAs the autoregulation should be normal in the involved areas; in fact, this was found to be the case by Skinhrfj et al. (1970). The reverse is held to be true by the hemodynamic hypothesis: in other words, the autoregulation is chronically impaired in those cortical areas perfused below the average normal value, namely, with marginal blood supply. In fact, quite recently loss of autoregulation has been observed in up to $90 \%$ of cases with TIA (Austin et al, 1978; Renou et al, 1978; Heil-brun etal, 1978).

Also, in PTIA relevant focal or diffuse alterations in CBF (Gratzl and Schmiedek, 1978; Austin etal., 1978; Heilbrun et al, 1978) have been reported, no differences thus being found between TIA and PTIA (Heilbrun et al, 1978). On the other hand these data do not appear to entirely solve the pathogenetic problem, first of all because the value of CBF determinations as a reliable index of neuronal function is debatable (Waltz, 1978); moreover, the topographical correlation between low $\mathrm{CBF}$ values and the 6

Loeb

size of the lesion is often unsatisfactory (Yamaguchi et al., 1971).

Therefore, the pathophysiology of TIA still remains somewhat obscure, even those authors — constituting the majority — who favor the embolic or thromboembolic pathogenesis do not seem to discard, at least for some cases, the 'hemodynamic theory'. As is well known, this last one postulates the superposition of transient reductions of perfusion pressure brought about by falls of systemic blood pressure and/ or cardiac output upon preexisting chronic focal reductions in $\mathrm{CBF}$ due to lesions of small or great arteries.

The embolic theory of TIA is supported by the following data (van der Drift and Kok, 1971; Russell, 1976): (a) the attacks, always sudden, do not usually bear any relationship to postural variations, hypotension or cardiac abnormalities; (b) the episodes do not occur within the same district: according to Waltz (1978), however, a stereotyped behavior can be accounted for even by embolization; (c) embolic sources can usually be identified; (d) emboli have been visualized during their progression within retinal vessels (Fisher, 1958; Russell, 1961, 1963, 1968; Ashby et al, 1963; Gunning et al, 1964), and (e) no attacks can be brought about by even considerably lowering the blood pressure in patients who were currently experiencing TIIAs (Loeb et al, 1961; Kendell and Marshall, 1963; Drake and Drake, 1968).

As far as PTIAs are concerned, it should be recalled that the attacks often have a gradual onset and usually recur within the same district; embolic sources have not generally been identified.

At present, it does not seem possible to reach a satisfactory conclusion as to the actual pathophysiological mechanisms underlying PTIAs.

However, the clinical differences with respect to TIAs outlined above may suggest the existence of a different pathophysiological mechanism as well.

The most interesting and intriguing problem raised by PTIAs, both from the pathogenetic and therapeutic point of view, is obviously that of the vulnerability to hypoxia of the central nervous system.

Quite a few more or less recent studies demonstrated that even an ischemia lasting $1-2 \mathrm{~h}$ does not necessarily lead the neuron to death (Hossmann and Sato, 1970; Hossmann and Olsson, 1970; Hossmann and Lechtape-Griiter, 1972). Therefore, it can be stated that under certain circumstances, even a global ischemia lasting up to $2 \mathrm{~h}$ can be endured by the brain without bringing about histologically visible alterations (Cantu and Ames, 1969; Crowell et al, 1979; Waltz et al, 1972). 
In fact, during carotid clamping for endarter-ectomy, alterations of the EEG and of cortical evoked potentials appeared only at values of 20-30 $\mathrm{ml} / 100 \mathrm{~g} / \mathrm{min}$ of CBF (Branston et al, 191A; Sharbroughetal, 1973).

In experimental models of ischemia (Yamaguchi et al, 1971) there can be found the whole transition from ischemic and active cells to ischemic inactive but still alive and ischemic dead ones. Perhaps, as suggested by Waltz (1978), reperfusion can bring some or many such neurons back to their normal levels of activity. At present no one can tell how long it takes for the whole process to develop in the clinical setting. In point of fact, a Todd paralysis (admittedly of hypoxic nature; Meyer and Portnoy, 1958) lasting up to 15 days or cases of PTIAs receding after 3 weeks can be taken as good examples of how the human brain can resist and recover from protracted ischemia.

Further clinical research on this topic therefore seems warranted.

Protracted Transient Ischemic Attacks

7

Treatment

Over the last twenty years anticoagulants, cervical endoarterectomy and more recently antiplatelet drugs and vascular microsurgery have been employed in cases with TIAs.

The value of these approaches has been difficult to assess mainly due to the huge variability of the natural history of TIAs. It seemed therefore useful to refer to some recent reports which represent the experience of various group of researchers or community studies.

The anticoagulant treatment seems beneficial in reducing the incidence of TIAs and /or completed strokes mainly in the first 3-6 months (Whisnant, 1977).

After 6 months there is no significant difference in morbidity and mortality between the treated and control groups (Whisnant, 1977). The need for wide randomized investigations is stressed by Toole etal. (1975).

If carefully monitored by regular controls of prothrombin time, the anticoagulant treatment turns out to be relatively safe (Whisnant et al, 1978). Aspirin seems to reduce the risk of subsequent completed strokes in males (Barnett, 1978), but the results of its therapeutic trial, although promising, cannot be considered as conclusive (Fields et al, 1978).

Endoarterectomy is indicated in patients with TIAs exhibiting ulcerated plaques and/or accessible stenoses of one or both carotids or sometimes vertebral arteries in the neck (Toole et al, 1975). In cases with carotid involvement surgery should not be unduly delayed (Millikan and McDowell, 1978). Associated diseases such as hypertension or myocardial infarction constitute, however, additional and unacceptable risks (Sundt et al, 1975).

The establishment of microsurgical anastomoses between the superficial temporal and

cortical middle cerebral arteries seems promising, at least in cases not amenable to conventional surgical techniques (Yasargil and Yonekawa, 1978; Austin et al., 1978).

Along with Millikan and McDowell (1978), however, it is reasonable to conclude that the indications and limits of the whole procedure await further assessment (Reichman, 1976).

If, on the other hand, one leaves aside for a moment the results of the long-term investigations and joint studies and tries to cope with the individual patient (Millikan, 1978), quite often a pervading feeling of helplessness may creep in.

To this account the reader might find it expedient to refer to the recent 'Guidelines for management of TIAs' (Sandok et al, 1978) with minor modifications, as follows:

Subject with Carotid TIAs

In the absence of relevant medical risk factors (severe hypertension and heart or lung diseases) and if an exhaustive angiographic study has disclosed a lesion relevant to the clinical picture without signs of diffuse or multiple involvement, surgery can be undertaken by a skilled operator. At any rate the angiographic risk, even when the femoral route is employed, cannot be overlooked and carefully estimated (Faught et al, 1979).

An anticoagulant treatment can be begun in cases with TIAs of less than 2 months duration not amenable to surgery, and should be pursued for at least $3-6$ months thereafter switching to aspirin.

The complications of the anticoagulant treatment should not be underestimated: the risk of intracranial hemorrhage in patients with TIAs of 55-74 years of age is about eight times greater in treated than in untreated cases.

Treatment with aspirin is begun in patients unfit for surgery, either following the initial course

8

of anticoagulants as described above or when the last episode occurred more than 2 months previously, being subsequently pursued at least for a 2 -year period free from further attacks.

Subjects with Vertebrobasilar TIAs Indications for surgical treatment are here even more selective and the efficacy of surgery far less established than in carotid TIAs (Blaisdell, 1973). Anticoagulant and antiplatelet therapies constitute, therefore, the mainstay of the treatment which should be carried out along the lines described above.

Conclusions

The existence of transient cerebrovascular episodes has been acknowledged since the 19th century, such episodes, however, must be correctly categorized as well as the other clinical aspects of cerebrovascular disorders.

Mainly due to practical therapeutic and/or preventive reasons, with the conventional and somewhat artificial heading of TIAs, transient attacks lasting less than $24 \mathrm{~h}$ have been labelled; to this arbitrary definition another one has been added, equally artificial to that of PTIA, comprising episodes receding over an average 3-week period.

It is quite apparent that TIAs and PTİAs share a common pathogenesis, clinical picture and treatment in spite of some difference, which, however, deserves further investigation over a sufficiently large case material.

One may wonder whether such an artificial distinction between TIA and PTIA should be maintained. At present, in view of the wide acceptance by the literature of the term TIA, it seems mandatory to outline the clinical features of equally transient ischemic episodes, which, however, for their surprisingly complete resolu- 
tion in spite of their longer duration with respect to TIAs seem to lend themselves to much more interesting speculations about their pathophysiology. From the therapeutic standpoint, moreover, the possibilities of surgical attempts at revascularization in these cases seem to be worth investigating on a large case material.

References

Alajouanine, T.H.; Lhermitte, F., and Gautier, J.C.: Transient cerebral ischemia in atherosclerosis. Neurology, Minneap. 10: 906-914 (1960).

Alajouanine, T.H. et Thurel, R.: La pathologie de la circulation cerebrate. Revue neurol. 65: 1276-1358 (1936).

Andral, G.: Corso di patologia interna. Collected by A. Latour, Italian version of the fifth French edition (Oliva, Milano 1853)

Ashby, M.; Oakley, N.; Lorentz, I., et al.: Recurrent transient monocular blindness. Br. med. J. ii: 894-897 (1963).

Austin, G.; Haugen, G., and Schuler, W.: Transient ischemic attacks and metabolic aspects of their relief by microneurosurgical anastomosis; in Fein and Reichman, Microvascular anastomoses for cerebral ischemia (Springer, New York

Baker, R.N.: Prospective study of transient ischemic attacks; in Toole, Moossy and Janeway, Cerebral vascular diseases, pp. 166-169 (Grune \& Stratton, New York 1971)

Blaisdell, W.: Extracranial arterial surgery in the treatment of stroke; in McDowell and Brennan, Cerebral vascular diseases: Trans. 8th Princeton Conf. (Grune \& Stratton, New York 1973).

Bland, W.C. (1889): Quoted by Wilson, S.A.K. and Bruce, A.N.: Neurology, vol. 3 (Butterworths, London 1955)

Boherave, H.: Opera omnia medica venetiis (Occhi, 1771).

Bouveret, L.: Aphasie, hemiplegie, apoplexie suite d'hemorragie gastrique. Autopsie. Revue Med. 19: 81-87 (1899).

Branston, N.M.; Symon, L.; Crockard, H.A., and Pasztor, E.: Relationship between the cortical evoked potential and local cortical blood flow Protracted Transient Ischemic Attacks

following acute middle cerebral artery occlusion in the baboon. Expl Neurol. 45: 195-208 (1974)

Buchner, F. (1939): Quoted by Ziilch, K.J.: Cerebral circulation and stroke. Introduction (Springer, Berlin 1971).

Bull, U.l Tongendorff, J.; Rothe, R. and Fischer, K.: Results of serial scintigraphy with "'mTc-per-technetate in comparison with angiography and computerized tomography in cerebrovascular diseases; in Lanksch and Kazner, Cranial computerized tomography, pp. 298-304 (Springer, Berlin 1976)

Caelius Aurelianus: De acutis morbis, lib. Ill (Ludguni, Rovillium 1565).

Canadian Cooperative Study Group: A randomized trial of aspirin and sulfinpyrazone in threatened stroke. New Engl. J. Med. 299: $53-59$ (1978).

Cantu, R.C. and Ames, A.A., Ill: Experimental prevention of cerebral vasculature obstruction produced by ischemia. J. Neurosurg. 30: $50-56$ (1969).

Chater, N.L. and Weinstein, P.R.: Progression of middle cerebral artery stenosis to occlusion without symptoms following superficial temporary artery bypass. Case report; in Fein and Reichman, Microvascular anastomoses for cerebral ischemia (Springer, New York 1978)

Constant, P.; Renou, A.; Caille, J., and Vernhiet, J.: CAT studies of cerebral ischemia; in DuBoulay-Moseley, Computerised axial tomography in clinical practise (Springer, Berlin 1976).

Corday, E. and Rothenberg, S.F.: The clinical aspects of cerebral vascular insufficiency. Ann. intern. Med. 47:626 (1957)

Crowell, R.M.; Olsson, Y.; Klatzo, I., and Ommaya, A.: Temporary occlusion of the middle cerebral artery in the monkey. Clinical and pathological observation. Stroke 1: 439-448 (1970).

Drake, W.H. and Drake, M.A.L.: Clinical and angiographic correlates of cerebrovascular insufficiency. Am. J. Med. 45: 253-270 (1968).

Drift, J.H. van der and Kok, N.K.D.: Transient ischaemic attacks; in Stocker, Kuhn, Hall, Becker and Van der Veen, Assessment in cerebrovascular insufficiency, pp. 132-135 (Thieme, Stuttgart 1971).

Durand-Fardell, M.: Traite du ramoUissement du cerveau (Bailliere, Paris 1843 ).

Faught, E.; Trader, S.D., and Hanna, G.R.: Cerebral complications of angiography for transient ischemia and stroke. Prediction of risk. Neurology, Minneap. 29: 4-15 (1979).

Fazio, C. e Loeb, C: Apoplessia transitoria e apoples-sia senza focolaio. Riv. Neurol. 18: 142-153 (1948).

Fields, W. S.; Lemak, N. A. Frankowski, R.F. and Hardy, R J : Controlled trial of aspirin in cerebral ischemia. II. Surgical group. Stroke 9: 309-317 (1978).

Fisher, CM.: Intermittent cerebral ischemia; in Wright and Millikan, Cerebral vascular diseases (Grune \& Stratton, New York 1958).

Grasset, J.: Lecons de clinique medicale, 3e ser. (Coulet, Montpellier/Masson, Paris 1891).

Gratzl, O. and Schmiedek, P.: Microneurosurgical arterial anastomoses in patients with prolonged reversible ischemic neurological deficits (PRINND); in Fein and Reichman, Microvascular anastomoses for cerebral ischemia (Springer, New York 1978).

Grillo, P. and Patterson, R.N.: Occlusion of the carotid artery. Prognosis (natural history) and the possibilities of surgical revascularization. Stroke 6: 17-20(1975).

Gunning, A.J.; Pickering, G.W.; Robb-Smith, A.H.T., et al.: Mural thrombosis of the internal carotid artery and subsequent embolism. Q. Jl Med. 33: 155-195 (1964).

Heilbrun, M.P.; Reichman, O.H.; Anderson, R.E., and Roberts, T.S.: Regional cerebral blood flow studies following superficial temporal-middle cerebral artery anastomosis; in Fein and Reichman, Microvascular anastomoses for cerebral ischemia (Springer, New York 1978).

Heymann, A., et al.: Report of the Joint Committee for Stroke Facilities. XI. Transient focal cerebral ischemia: epidemiological and clinical aspects. Stroked: $276-287$ (1974),

Hossmann, K.A. and Lechtape-Griiter: Blood flow and recovery of the cat brain after complete ischemia for 1 hour; in Fieschi, Cerebral blood flow and intracranial pressure, pp. 318-322 (Karger, Basel 1972).

Hossmann, K.A. and Olsson, Y.: Suppression and recovery of neuronal function in transient cerebral ischemia. Brain Res. 22: 313-325 (1970).

Hossmann, K. A and Sato, K. Recovery of neuronal function after prolonged cerebral ischemia Science 168: 375-376 (1970).

Hutchinson, E.C. and Acheson, E.J.: Strokes. Natural history, pathology and surgical treatment (Saunders, London 1975).

10

Loeb

Jackson, H. (1888): in Taylor, Holmes and Walshe,

Selected writings of J.H. Jackson, vol. 2, pp. 365-

392 (Staples Press, London 1958). Kendell, R.E. and Marshall, J.: Role of hypotension in

the genesis of transient focal cerebrat ischaetic an

attacks. Br. med. J. X: 344-348 (1963). Kikuchi, H. and Karasawa, J.: Clinical experiences

with STA-MCA anastomosis in 54 cases; in Fein

and Reichman, Microvascular anastomoses for

transverse tomography in cerebrovascular disease.

Neurology, Minneap. 26: 929-930 (1976). Lamy, H.: Syphilis des centres nerveux; dans Charcot,

Bouchard et Brissaud, Traite de medecine, tome VI

(Masson, Paris 1894). Lhermitte, J.: Les idees n
l'hemiplegie transitoire et du ramollissement

cerebral. Encephale 23: 27-39 (1928). Liliequist, B.:

Cerebrovascular diseases and head injuries; in

Marttila, Proc, 22nd Scand. Congr. Neurology.
Acta neurol. scand. 57: suppl. 67, pp. 165-175

Acta neurol. scand. 57: suppl. 67, pp. 165-175
(1978). Loeb, C: Clinical survey of patients with reversible

ischemic attacks. Int. Symp., Milan 1977. Eur.

Neurol, (in press, 1978a). Loeb, C: Reversible ischemic attacks. Cerebrovascular

disorders and stroke. Int. Symp., Florence 1978

(Raven Press, in press, 1978b). Loeb, C; Garello, L. e Pastorino, P.: Aspetti clinici

deH'insufficienza cerebrovascolare. Sist. Nerv. 13:

334-351 (1961). Loeb, C. and Priano, A.: Strokes with full recovery. A

reappraisal; in Meyer, Lechner, Reivich and Eich-

horn, Cerebral vascular disease, pp. 15-21

(Thieme, Stuttgart 1973). Loeb, C. et Priano, A.: Accidents cerebrovasculaires

Evolution regressive complete tardive. Revue

neurol. 131: 873-878 (1975). Loeb, C; Priano, A., and Albano, C: Clinical features

and long term follow-up of patients with reversible

ischemic attacks (RIA). Acta neurol. scand. 57:

471-480(1978). Lyons, C: Progress report of joint study of extracranial occlusion; in Millikan, Siekert and

Whisnant, Cerebral vascular diseases, pp. 221-235

(Grune \& Stratton, New York 1965). McDowell, F.H.; Potes, J., and Groch, S.: The natural 
Meyer, J.S. and Portnoy, H.: Localized cerebral hypoglycemia simulating stroke. Neurology, Minneap. 8: 601-614 (1958).

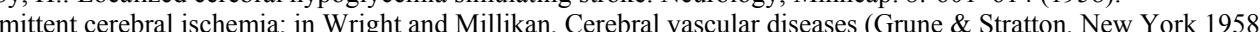

Millikan, C.H.: in Siekert, Cerebrovascular Survey Report for Joint Council Subcommittee on Cerebrovascular Disease NIIH, pp. 141-171 (Whiting Press, Rochester 1976).

Millikan, C.H.: Clinical investigation of things or people. Neurology, Minneap. 28: 744-745 (1978).

Millikan, C.H. and McDowell, F.H.: Treatment of transient ischemic attacks. Stroke 9: 299-308 (1978).

Morgagni, G.B.: Delle sedi e cause delle malattie, con note di F. Chaussier e N.P. Adelon (Sansone Coen, Firenze 1839).

Neisser, C: Die paralytischen Anfalle (Stuttgart 1894).

Oltenau-Nerbe, V.; Schmiedek, P.; Kazner, E.; Lanksch, W., and Marguith, F.: Comparison of regional blood flow and computerized tomography in patients with cerebrovascular disease and brain tumors; in Lanksch and Kazner, Cranial computerized tomography, pp. 305-308 (Springer, Berlin 1976).

Oppenheim, H.: Trattato delle malattie nervose, vol. 2 (SEİ, Milano 1905).

Osier, W. (1896): Quoted by Wilson, S.A.K. and Bruce, A.N.: Neurology, vol. 3 (Butterworths, London 1955).

Paulson, O.B.: Cerebral apoplexy (stroke). Pathogenesis, pathophysiology and therapy as illustrated by regional blood flow measurement in the brain. Stroke 2: 327-360(1971).

Peabody, G.L.: Relations between arterial disease and visceral changes. Trans. Ass. Am. Physns 6: 154-195 (1891)

Perrone, P.; Candelise, L.; Scotti, G.; Grandi, C. de, and Scialfa, G.: CT evaluation in patients with transient ischemic attack. Correlation between clinical and angiographic findings. Eur. Neurol, (in press). Protracted Transient Ischemic Attacks

Pessin, M.S.; Duncan, G.W.; Mohr, G.P., and Poskanzer, D.C.: Clinical and angiography features of carotid transient ischemic attacks. New Engl. J. Med. 296: 358-362 (1977)

Reichman, O.H.: Neurosurgical microsurgical anastomosis for cerebral ischemia. Five years experience; in Schi

Rein, H. (1931): Quoted by Zttlch, K.J.: Cerebral circulation and stroke. Introduction (Springer, Berlin 1971).

Renou, A.M.; Caille, J.M. et Constant, P.: Vaso-reactivite a l'alfatesine en pathologie cerebrale. J. Neuroradiol. 5: 257-266 (1978).

Ring, A.: Middle cerebral artery. Anatomical and radiographic study. Acta radiol. 57: 289-300 (1962).

Rokitansky, C: A manual of pathological anatomy. 1824-1844 (Sydenham Society, London 1856).

Russell, R.W.R.: Observation on the retinal bloodvessels in monocular blindness. Lancet $i i$ : 1422-1428(1961).

Russell, R.W.R.: Atheromatous retinal embolism. Lancet $i i: 1354-1356$ (1963).

Russell, R.W.R.: The source of retinal emboli. Lancet $i i:$ 789-792 (1968).

Russell, R.W.R.: In cerebral arterial disease, pp. 125-145 (Churchill-Livingstone, Edinburgh-London 1976).

Sandok, B.A.; Furlan, A.J.; Whisnant, J.P., and Sundt, T.M.: Guidelines for the managem

Sharbrough, F.W.; Messick, J.M., and Sundt, T.M., Jr.: Correlation of continuous electroencephalograms with cerebral blood flow measurements during carotid endarterectomy. Stroke 4: 674-683 (1973).

Skinh^j, E.; Hoedt-Rasmussen, K.; Paulson, O.B., and Lassen, N.A.: Regional cerebral blood flow and its autoregulation in patients with transient focal cerebral ischemic attacks. Neurology, Minneap. 20 : 485-493 (1970). Souques, A.: Hemiplegie; dans Charcot, Bouchard et Brissaud, Traite de medecine, tome VI (Masson, Paris 1894).

Sundt, T.M.; Sandok, B.A., and Whisnant, J.P.: Carotid endarterectomy. Complications and preoperative assessment of risk. Mayo Clin. Proc. 50: 301-306 (1975).

Toole, IF.; Janeway, R.; Choi, K.;Cordell, R.; Davis, C.; Johnston, F., and Miller, H.S.: Transient ischemic attacks due to atherosclerosis. A prospective study of 160patients.|ArchsNeurol. 52:5-12 (1975).

Waltz, A.C.: Anatomy and physiology pertinent to stroke; in Fein and Reichman, Microvascular anatomoses for cerebral ischemia (Springer, New York 1978).

Waltz, A.G.; Sundt, T.M., Jr., and Michenfelder, J.D.: Cerebral blood flow during carotid endarterectomy. Circulation 45: 1091-1096 (1972).

Weiss, M. (1882): Quoted by Wilson, S.A.K. and Bruce, A.N.: Neurology, vol. 3 (Butterworths, London 1955).

Whisnant, J.P.: Epidemiology of stroke. Emphasis on transient cerebral ischemic attacks and hypertension. Stroke 5: 68-70 (1974).

Whisnant, J.P.: Transient ischaemic attacks. Clin. Exp. Neurol., Proc. Aust. Ass. Neurol. 14: 1-7 (1977).

Whisnant, J.P.; Niall, E.F.; Cartlidge, M.B., and Elveback, L.R.: Carotid and vertebral-basilar transient ischemic attacks: effect of anticoagulants, hypertension, and cardiac disorders on survical and stroke occurrence. A population study. Ann. Neurol. 3: 107-115 (1978).

Wilson, S.A.K. and Bruce, A.N.: Neurology, vol. 3 (Butterworths, London 1955).

Yamaguchi, T.; Waltz, A.G., and Okazaki, H.. Hyperemia and ischemia in experimental infarction. Correlation of histopathology and regional blood flow. Neurology 21: 565-578 (1971).

Yasargil, M.G. and Yonekawa, Y.: Experiences with the STA-cortical MCA anastomosis in 46 cases; in Fein and Reichman, Microvascular anastomoses for cerebral ischemia (Springer, New York 1978).

Yates, P.O.: The pathogenesis of transient attacks; in Gillingham, Mawdsley and Williams, Stroke, pp. 178-187 (Churchill-Livingstone, Edinburgh London 1976). 